Christo Moskovsky and Alan Libert. Essays on Natural and Artificial Languages. Frankfurt am Main: Peter Lang. 2009. ix+188 pp.

\title{
Reviewed by Federico Gobbo
}

Interlinguistic research, where planned languages are compared with natural languages, is rare, as too few scholars consider planned languages an object worthy of serious, objective study. This book is an exception. By "Artificial Language" (AL) the authors mean the traditional definition of international auxiliary languages, i.e. language systems planned as a tool of communication between speakers of different native languages in an international context. Hence, languages planned for fiction or other literary purposes (such as Klingon) are excluded by their analysis. The book is a collection of six essays that can be classified in the field of typology or language universals, covering a range of topics. With the notable exception of the first essay, which has a more general, philosophical perspective on the phenomenon of AL planning, the essays take a specific grammatical feature, such as passives (fourth essay), which is explained in its manifestations both in natural and in artificial languages. As a conclusion to each essay the authors offer recommendations for the would-be AL planner about the most effective strategy to pursue in constructing a new project.

A major point of interest in the book is the fact that a priori, mixed and a posteriori languages - following the taxonomy proposed by Couturat and Leau (1903) - are treated without any regard for their evolution, if any. In other words, there is no prejudgment based on the "success" of the AL in terms of adoption or sociolinguistic use: Esperanto or IALA's Interlingua are thus put alongside Kosmos or Eurolengo. Although this procedure can be seen as a severe limitation in the essays, in fact it is not, because most ALs did not produce a relevant linguistic corpus, and the authors argue that the most ticklish points in grammar are unclear exactly for this reason. For instance, Gode and Blair (1951:25) say that "relative pronouns are primarily of the type in which the object of the verb happens to be logically identical with the subject." The authors rightly comment (37): "the question is what is meant by 'primarily'? Does it allow for non-subject orentation, or for the RP [relative pronoun] to be something other than a verbal object (e.g. the object of a preposition), or both?" In this specific case, a data-driven investigation on a corpus of Interlingua texts is suggested. In other cases, such as reflexives in the Blue Language by Bollack (1900), there is a mismatch between the rule in the grammar and the examples given by the language planner (second essay, 39). 
In practice, there are two considerations that should be put in evidence: the most interesting ALs are a posteriori, and they are typologically Indo-European, if not actually part of Standard Average European (SAE). This is hardly surprising, as the native languages of most AL planners belong to that typological group.

A place apart is given to Esperanto, as its evolution is well documented. Authors refer mainly to prescriptive grammars, from Zamenhof's (1905) to Wennergren's (2005), which are freely available on the web, so easily accessible by Esperanto speakers, giving interesting insights to specialists in Esperanto studies.

A minor criticism that can be made of the volume is poor proof-reading, in particular in the bibliography, which is exceptionally rich in authentic sources of ALs. For example, in the title of Couturat and Leau (1903) readers read the English word "language" instead of the correct French one "langue" (177), and in Wennergren (2005) the publisher of the print edition (ELNA) is missing (187).

\section{References}

Bollack, L. 1900. Abridged Grammar of the Blue Language (English version by Professor Tischer). Paris: Editions of the Blue Language.

Couturat, L. and L. Leau. 1903. Histoire de la langue universelle. Paris: Hachette.

Wennergren, B. 2005. Plena manlibro de Esperanta gramatiko. El Cerrito: ELNA. http://bertilow. com /pmeg/elshutebla/pmeg_14.0.pdf.

Zamenhof, L. L. 1905. Fundamento de Esperanto. Paris: Hachette. http://www.akademio-deesperanto.org/fundamento/index.html.

\section{Reviewer's address}

\section{DICOM}

Università degli Studi dell' Insubria

via Mazzini 5

I-21100 Varese, Italy

\section{About the reviewer}

Federico Gobbo is lecturer in history of computing at the University of Insubria (Italy) and in computational linguistics in the University of Milano-Bicocca (Italy). His research interests include computational linguistics, interlinguistics, language planning, history of computing and computing and philosophy. 